\title{
Artemia salina
}

MUNTEANU Constantin, DUMITRAȘCU Mioara

SC Biosafety SRL-D;

Artemia salina (L.) is a primitive aquatic arthropod (salt lakes) of the Artemiidae family (figure 1) with an age of about 100 million years. Linný (1758) described it as Cýncer salinus but 61 years later, Leach (1819) transferred it to Artemia salina.

It was reported for the first time in Urmia Lake in 982 by a Iranian geographer (Asem, 2008).

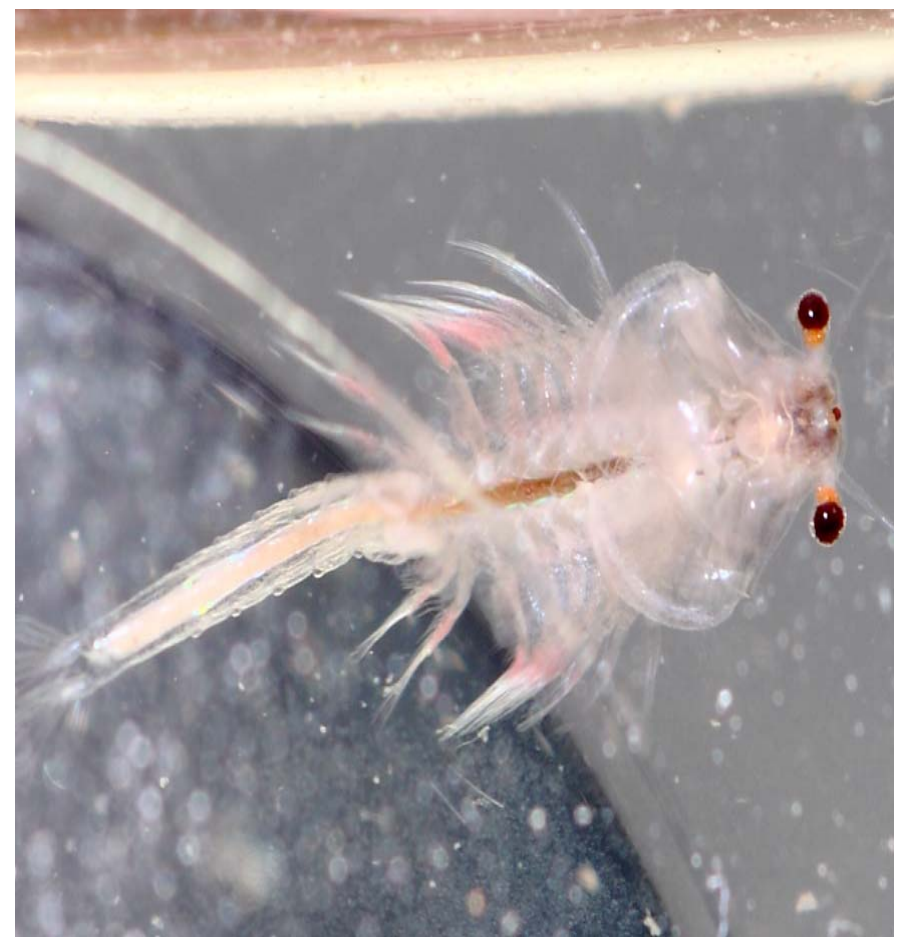

Figura 1. Artemia salina

\section{Species ecology}

Artemia salina lives only in lakes and ponds with high salinity, which varies between 60-300 ppt. It was also discovered in Elkhorn Slough (California), which communicates directly with the sea. It is a species endemic to the Mediterranean, but is found on all continents (figure 2).

In our country is reported in salt lakes (Bear Lake, Ocna Sibiu, Techirghiol, Braila Salt Lake, etc.) contributing to the formation of sapropelic mud used in peloidotherapy.

A. salina is associated with current or past commercial exploitation of salt (Abatzopoulos et al., 2002, quoted by Abatzopoulos et al., 2010).

Can tolerate large amounts of salt (up to 300 grams of salt per liter of water) and can live in quite different solutions of seawater such as potassium permanganate and silver nitrate.Iodine, which is found frequently in salt for human use, is harmful to this species.

\begin{tabular}{|l|l|}
\hline \multicolumn{2}{|c|}{ Scientific classification } \\
\hline Kingdom: & Animalia \\
\hline Phylum: & Arthropoda \\
\hline Subphylum: & Crustacea \\
\hline Class: & Branchiopoda \\
\hline Order: & Anostraca \\
\hline Family: & Artemiidae \\
\hline Genus: & Artemia \\
\hline Species: & $\begin{array}{l}\text { Artemia salina } \\
\text { (Linnaeus, 1758) }\end{array}$ \\
\hline
\end{tabular}

These animals have the ability to reduce the osmotic pressure of haemolymph by $\mathrm{NaCl}$ excretion against the concentration gradient. Has been shown to developed a mechanism to maintain haemolymph extreme hypotonic in saline extreme media (Croghan, 1957).

Also, this species can survive in water with high oxygen deficiency. Minimum concentration of oxygen for an adult is very low, 0.5 milligrams per liter, and for naupliia even less than 0.3 milligrams per liter. Typical salt lakes have seasonal or cyclical droughts, periods when completely dry. During this process salt water concentrations ranging from ideal to barely tolerable. 


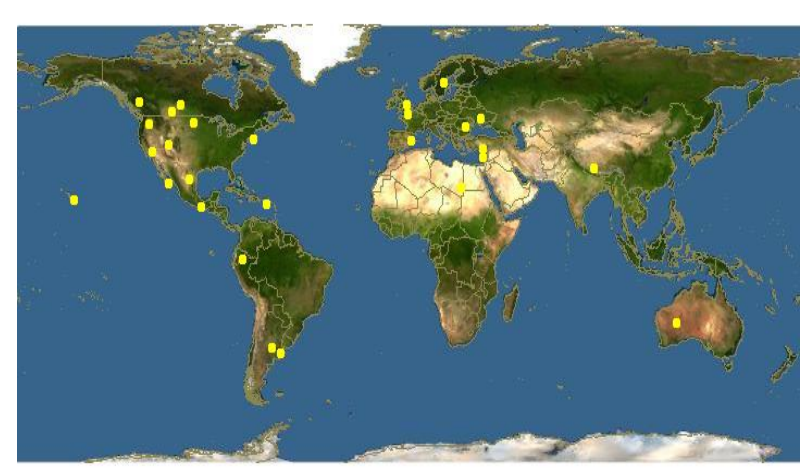

Figure 2. Artemia salina worldwide distribution (Global Biodiversity Information Facility Database http://www.discoverlife.org)

\section{Description}

The body consists of three segments: head, thorax and abdomen. The species presents sexual dimorphism, the main morphological differences between males and females were observed in maximum distance between compound eyes, length of first antenna, the width of the third abdominal segment, the total length, diameter of compound eye, length of abdomen.

The adult male reach to $8-10 \mathrm{~mm}$ long, and the female $10-12 \mathrm{~mm}$. Adults have three eyes and 11 pairs of legs.

Adult color varies depending on the concentration of salt in the water from green tored (high concentrations are red). Their blood contains pigment hemoglobin.

Lack of competition in this extreme environment allows them to develop large populations when conditions are suitable for reproduction (heat, sunlight, wide range of salt concentrations).

This organism can withstand long periods of drought and cyst stage to resume the life cycle when conditions are suitable for development and reproduction.

Males have two reproduction organs. The uterus of one female of A. salina may contain up to 200 eggs. It is an oviparous and ovoviviparous species.

The two methods of reproduction alternates depending on the conditions of life: are ovoviviparous when they are favorable and when become unfavorable, tend to be oviparous.

They produce eggs, which float on water and can develop either directly into nauplia (larvae) or unfavorable environmental conditions (water drying) is transformed into cysts (dormant forms of life) that can survive long periods of drought. If environmental conditions improve, cysts are "re-vitalizing" and hatch nauplia.

Under natural conditions Artemia salina feeds with algae, protozoa and detritus. Feeding mode is active non-selective filter; removes suspended particles less than 40-60 $\mathrm{mm}$.

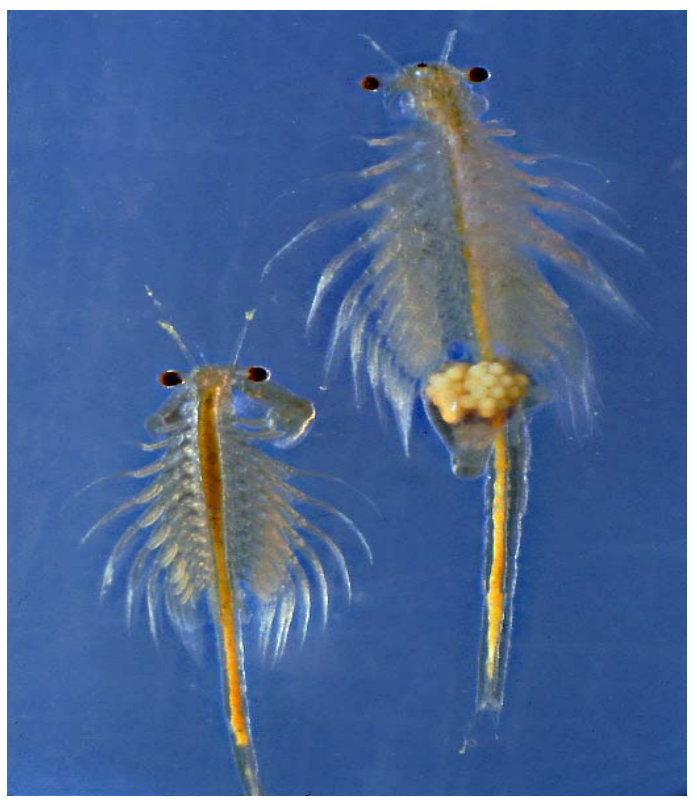

Figure 4. Individuals of the Artemia salina

\section{Life cycle}

Mode of reproduction is controlled by environmental factors: the concentration of oxygen in water and its fluctuation, the type of food, salinity, etc. (table 1). There was a correlation between water salinity level and method of reproduction. Ovoviviparous to less than 150 ppt salinity and oviparous predominantly between $150-200$ ppt salinity

Table 1. The modalities of Artemia salina reproduction

\begin{tabular}{|l|l|}
\hline \multicolumn{2}{|c|}{ REPRODUCTION } \\
\hline \multicolumn{1}{|c|}{ OVIPAROUS } & \multicolumn{1}{c|}{ OVOVIVIPAROUS } \\
\hline $\begin{array}{l}\text {-- low } \mathrm{O}_{2} \text {-content } \\
\text { (such as in high } \\
\text { salinity) }\end{array}$ & $\begin{array}{l}\text {-high oxygen content } \\
\text { (such as in low salinity) }\end{array}$ \\
\hline $\begin{array}{l}\text { - strong } \mathrm{O}_{2-} \\
\text { fluctuations }\end{array}$ & - minor $\mathrm{O}_{2}$-fluctuations \\
\hline $\begin{array}{l}\text { - Fe-rich food (such } \\
\text { as green algae) }\end{array}$ & $\begin{array}{l}\text { - Fe-low food (such as } \\
\text { organic debris) }\end{array}$ \\
\hline
\end{tabular}


Vol.2, Nr.4, 2011

Oviparous reproduction

After copulation fertilized egg develops into a gastrula stage and are surrounded by a tough brown crust consists of chitin, lipoproteins, etc.

Cysts thus formed are released into the water and must pass through a drying process. Only when this initial dehydration occurred, the cysts can get free larvae when conditions become favorable.

\section{Ovoviviparous reproduction}

The fertilized egg develops to the stage of gastrulă, but instead of being confined, still gastrula differentiate into female body, the larvae called nauplia. Eggs hatch nauplia which will have a whitish colour. Nauplia are free fins larvae.

Cysts $(0.2-0.3 \mathrm{~mm})$ turn into larvae water swimmer, nauplia $(0.45 \mathrm{~mm})$ in a period of $24-$ 36 hours. Complete hydration cyst takes about an hour. Depending on food availability, nauplia will reach adults (max. $12 \mathrm{~mm}$ ) within 3 weeks.

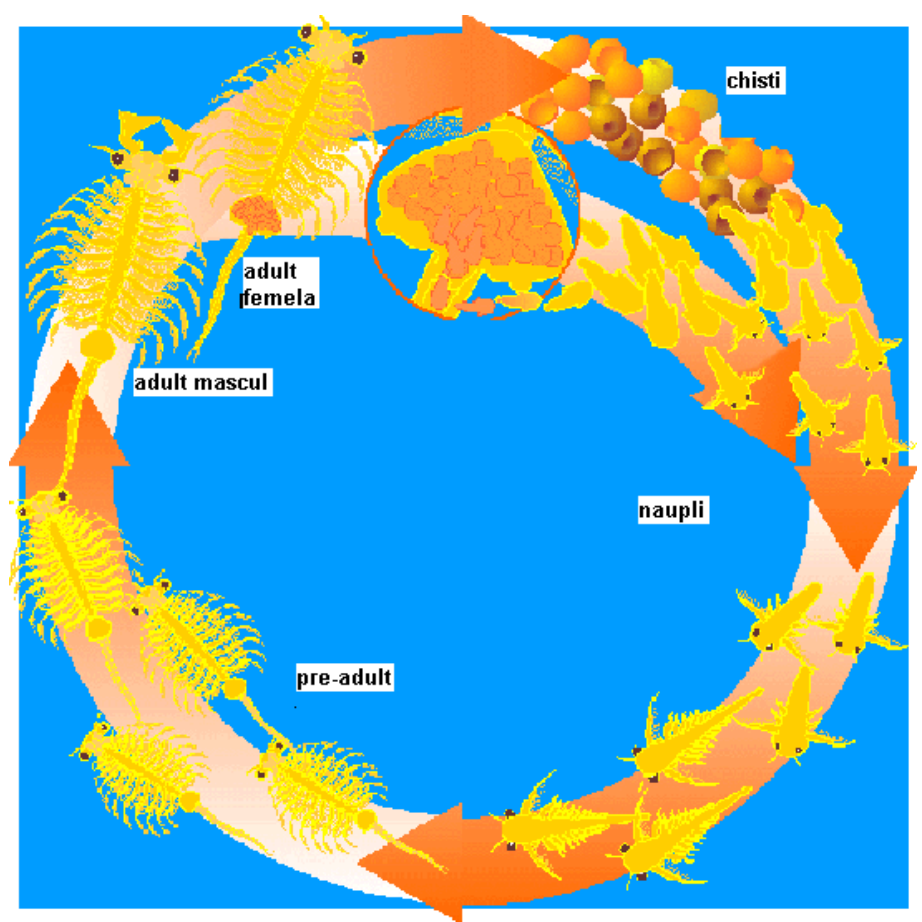

Figure 5. Artemis salina life cycle (http://brineshrimp.wordpress.com/)

Nauplia turns into reproductive adults that produce live young in rapid succession when conditions are favorable and cysts that can survive dry conditions for years if conditions begin to become less favorable.
In order to result free fins nauplia from cysts, they need water (hydration) and oxygen to initiate and complete the metabolism.

\section{$\Rightarrow \quad$ Cysts}

Cysts are very resistant to extreme conditions, lasts up to $80 y$ C. Hydrated cysts die at temperatures below $0 y ́ \mathrm{C}$ and greater than $40 y$ C. The higher salinity of $70 \mathrm{ppt}$, naupliia will not be able to hatch due to osmotic gradient too high. At less than 5 ppt salinity, cysts will hatch, but nauplia results will die quickly.

Dehydrated cysts measuring between 200270 microns and an average weight of 3.5 micrograms.

Cysts are able to survive in contact with aggressive liquids, extreme dryness, lack of of oxygen and pesticides influence. For example, in the United States in 1976, during a drilling operationin the Great Salt Lake in Utah, A. salina cysts were found in thesoil sample between two layers of salt. Carbon analysis showed that age radiactiv cysts would be 10,000 years. (artemiaworld.com ).

\section{$\Rightarrow \quad$ Nauplia}

Have optimal growth at $28{ }^{0} \mathrm{C}$ and $35 \mathrm{ppt}$. Lethal temperature limits are $0{ }^{\circ} \mathrm{C}$ and $37-38^{\circ}$ C.

Larvae have only one eye (photoreceptor). Later, it developed two eyes, but the initial eye remains, resulting three eyes. Nauplia are phototactic, while adults not. They swim through the water column (phototaxis) using antennas. Mandibles are used to filter water and phytoplankton.

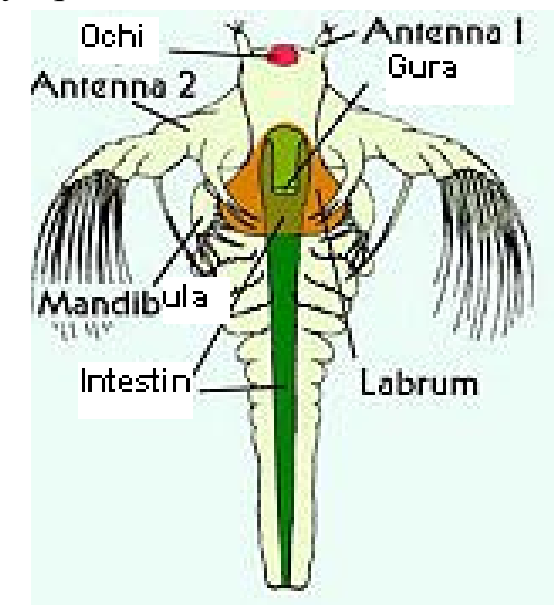

Figure 6. Anatomical characteristics of nauplia of Artemia salina 


\section{$\Rightarrow \quad$ Adults}

Adults swim using swim / filter feeding appendages. Median eye is accompanied by two lateral compound eyes. A simple brain formed a ring like structure around the mouth (typical of most invertebrates). Females develop eggs in a ventral egg sac with a rapid rate under favorable conditions.

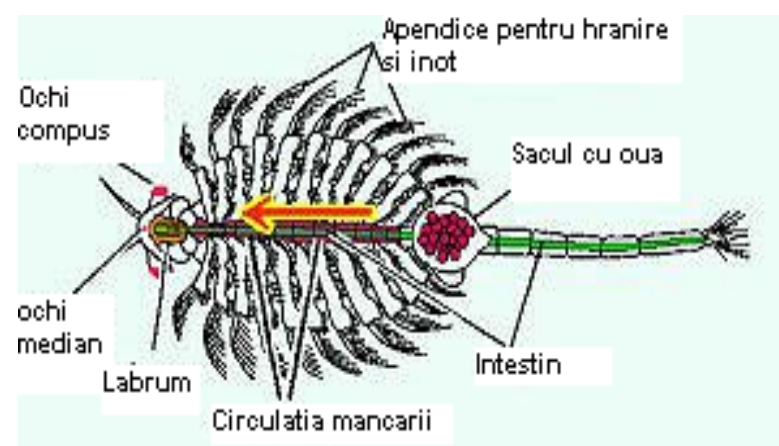

Figure 7. Anatomical characteristics of Artemia salina adult

\section{Importance}

Artemia salina species individuals, especially in stage nauplia, are used in aquaculture as live food for commercial growth (in incubators) of many species of fish and shellfish.

Resilience of these animals makes them ideal for testing samples in the experiments. Artemia salina is one of the organisms used regularly for toxicity testing of various chemicals.

Together with other bodies formed by decomposition salt lake bottom mud used to treat various rheumatic , gynecological, endocrine diseases, etc.

Salt water and mud from lake Ursu heliothermal contain hormones released by Artemia salina: human estrogen-like SU 95\%, respectively human progesterone-like 0.7 to 0.8 mg\% (Stoicescu Munteanu, 1977). They are used to treat gynecological diseases: ovarian failure, infertility, etc.

\section{References}

1. ABATZOPOLULOS T., BEARDMORE J., CLEGG J. and SORGELOOS P. (2010). Artemia. Basic and applied biology. Kluwer Academic Publishers.

2. ASEM A., RASTEGAR-POUYANI N. and RIOS-ESCALANTE P. (2010). The genus Artemia Leach, 1819 (Crustacea: Branchiopoda). I. True and false taxonomical descriptions. Lat. Am. J. Aquat. Res. v.38 n.3

3. CROGHAN C. (1957). The osmotic and ionic regulation of Artemia salina (L.). Department of Zoology, University of Cambridge.

4. MUÑOZ J., GÓMEZ A., GREEN A., FIGUEROLA J., AMAT F. and RICO C. (2008). Phylogeography and local endemism of the native Mediterranean brine shrimp Artemia salina (Branchiopoda: Anostraca). Molecular Ecology 17, 3160-3177.

5. STOICESCU C. and MUNTEANU L. (1977). Natural curative factors of the main balneoclimateric resorts in Romania. Edit. SportTurism, Bucharest.

6. VOS J. (1979). Brine shrimp (Artemia salina) inoculation in tropical salt ponds: a preliminary guide for use in Thailand. FAO Associate Expert (Culture of Food Organisms) National Freshwater Prawn Research and Training Center Freshwater Fisheries Division, Department of Fisheries Ministry of Agriculture and Cooperatives. Thailand.

7. VOS J. and de la ROSA NYMPHA. (1980). MANUAL ON ARTEMIA PRODUCTION IN SALT PONDS IN THE PHILIPPINES. FAO/UNDP-BFAR Brackishwater Aquaculture Demonstration and Training Project PHI/75/005

http://www.discoverlife.org/mp/20q? search=Artemia + salina http://www.artemiaworld.com/home/ http://jeb.biologists.org/content/35/1/219.full.pdf http://jgp.rupress.org/content/14/6/753.full.pdf http://www.drvoigt-consulting.de/background.htm http://www.isamm.org/artemia-salina.htm http://www.michaelsharris.com/12ubio/text/projects/brin eshrimplab.htm 